\title{
Towards universal health coverage: what are the system requirements for effective large-scale community health worker programmes?
}

\author{
Uta Lehmann, ${ }^{1}$ Nana A Y Twum-Danso, ${ }^{2}$ Jennifer Nyoni ${ }^{3}$
}

\begin{abstract}
To cite: Lehmann U,
Twum-Danso NAY, Nyoni J.

Towards universal health

coverage: what are the system requirements for effective largescale community health worker programmes? BMJ Glob Health 2019;4:e001046. doi:10.1136/ bmjgh-2018-001046
\end{abstract}

Handling editor Kerry Scott

Received 7 July 2018

Revised 20 September 2018 Accepted 24 September 2018

Check for updates

(c) Author(s) (or their employer(s)) 2019. Re-use permitted under CC BY-NC. No commercial re-use. See rights and permissions. Published by BMJ.

${ }^{1}$ School of Public Health, University of the Western Cape, Cape Town, South Africa ${ }^{2}$ Independent consultant, Accra, Ghana

${ }^{3}$ World Health Organization, Regional Office for Africa, Health Systems and Services Cluster, Brazzaville, Congo

Correspondence to Professor Uta Lehmann; ulehmann@uwc.ac.za

\section{ABSTRACT}

Against the background of efforts to strengthen health systems for universal health coverage and health equity, many African countries have been relying on lay members of the community, often referred to as community health workers (CHWs), to deliver primary healthcare services. Growing demand and great variability in definitions, roles, governance and funding of CHWs have prompted the need to revisit CHW programmes and provide guidance on the implementation of successful programmes at scale. Drawing on the synthesised evidence from two extensive literature reviews, this article determines foundational elements of functioning CHW programmes, focusing in particular on the systems requirements of large-scale programmes. It makes recommendations for the effective development of large-scale CHW programmes. The key foundational elements of successful CHW programmes identified are (1) embeddedness, connectivity and integration into the larger system of healthcare service delivery; (2) cadre differentiation and role clarity in order to maintain clear scopes of work and accountability; (3) sound programme design based on local contextual factors and effective people management, and (4) ongoing monitoring, learning and adapting based on accurate and timely local data in order to ensure optimal fit to local context since one size does not fit all. We conclude that $\mathrm{CHWs}$ are an investment in health systems strengthening and community resilience with enormous potential for contributing to universal health coverage and the sustainable development goals if well designed and managed. While the evidence base is uneven and mixed, it provides extensive insight and knowledge to strengthen, scale up and sustain CHW programmes throughout Africa.

\section{INTRODUCTION}

Ensuring healthcare is available and accessible to all has been a central but elusive goal for health systems in Sub-Saharan Africa as elsewhere around the world, ${ }^{1}$ due to health system challenges such as weak governance, lack of human resources, limited financial resources, erratic supply chains and poorly developed infrastructure, as well as conflict and disease outbreaks in several countries.

\section{Summary box}

- Community health workers (CHWs) have long been recognised as important contributors to community-based health services, but programmes have historically failed due to poor conceptualisation and implementation.

- Key foundational elements of successful CHW programmes include embeddedness, cadre differentiation, sound programme design, and ongoing monitoring, evaluation and adaptation.

- Large-scale CHW programmes constitute a strong health systems foundation for universal health coverage but cannot replace professional health workers.

- Innovative strategies for sustainable financing of large-scale CHW programmes must be sought, as there are limitations and costs to $\mathrm{CHW}$ volunteerism.

The African region in particular has been severely constrained in its ability to deliver the health services required to achieve universal health coverage (UHC), carrying $24 \%$ of the global burden of disease but only $3 \%$ of the global health workforce. This problem is often compounded by the inequitable distribution of the available health workforce within the countries, with the rural areas being the most deprived.

Health systems strengthening for UHC has therefore become a key priority for health in Africa, as represented in WHO's recent integrated action framework entitled 'Leave no one behind'.

Against this background many African countries have been relying on lay health workers in communities, known by many different names, but generically called community health workers (CHWs), to provide health services in communities. Their critical role in addressing the Ebola virus disease outbreak in West Africa in 2014 and 2015 reiterated their importance as mediators between 
communities and the formal health system. Yet, while there is widespread acknowledgement of their potential in providing the foundation for UHC, CHW programmes are often poorly conceptualised, planned and managed. This paper reviews the evidence of the effectiveness and shortcomings of CHW programmes to date, and presents foundational elements that are likely to increase effectiveness with a focus on the systems requirements of large-scale programmes.

This paper has its origins in a technical paper commissioned by WHO/Regional Office for Africa on the state of the evidence of CHWs, as well as policy options for national governments. The technical paper, ${ }^{2}$ which remains unpublished, also led to a policy brief, which this paper draws on. ${ }^{3}$ The authors conducted a review of relevant literature, drawing specifically on a range of systematic, narrative and scoping reviews, ${ }^{4-8}$ one of which emanated from work cowritten by the first author (UL). ${ }^{8}$

\section{A brief history of CHW programmes}

The vast and diverse history of CHW programmes internationally has recently been concisely summarised by Perry and colleagues. ${ }^{59}$ Training (often illiterate) community members to perform specific health service functions on a large scale has its (documented) origins in China in the 1950 s, in what came to be known internationally as the barefoot doctors programme. ${ }^{\mathrm{i}}$ Barefoot doctors became models and were emulated by countries in Africa, Asia and Latin America from the 1960s. The Alma Ata Declaration of 1978 established CHWs as essential elements of a comprehensive primary healthcare approach, 'suitably trained socially and technically to work as a health team and to respond to the expressed health needs of the community'.

There were several examples of large-scale CHW programmes in Africa in the 1960s to 1980s (eg, Tanzania, Malawi, Mozambique and Zimbabwe) driven by the transformative rationale of the Alma Ata Declaration. ${ }^{10}$ With the oil crisis and the world economic recession of the 1970s, and subsequent structural adjustment programmes, many programmes collapsed-a collapse further facilitated by the fact that many large-scale programmes suffered from conceptual and implementation problems such as 'unrealistic expectations, poor initial planning, problems of sustainability, and the difficulties of maintaining quality' ( $\left.{ }^{11}: 352\right)$ - a danger facing many programmes again today.

The recent renewal of interest in CHW programmes (and in Primary Health Care and community health systems more generally) in Africa (and internationally) has its roots in programmatic needs for incommunity providers exacerbated by the continuing constraints in

${ }^{\mathrm{i}}$ The great diversity of traditional health practitioners is not taken into account here. formally trained health personnel. Such programmes prominently include communicable and non-communicable diseases and maternal and child health (MCH).

\section{The state of the evidence to date}

The renewed interest in CHW programmes has been accompanied by increased research productivity in the field. There has been a virtual explosion of scientific evidence on roles, activities and effectiveness of CHWs in low-income and middle-income countries (LMICs), and particularly in Africa, over the past few years. ${ }^{8}$ A large number of guides, substantial evaluation reports and numerous online resources, such as CHW Central (http://www.chwcentral.org/), provide further data, evidence and advice for CHW policy making in African countries. ${ }^{\text {ii }}$

Despite the volume of literature, organised knowledge of CHW programmes, their effectiveness remains surprisingly limited. ${ }^{8}$ First, the literature reflects the already mentioned diversity of the field, covering different programmes, types and roles of CHWs, and management areas. Only few articles address issues of scale-up of programmes, or of policy and systems design and implementation specifically.

Second, much of the literature remains descriptive and consists of single case studies, with so far few articles that integrate and conceptualise the empirical work. Very few of the programmes studied were operating at scale. ${ }^{7}$ Nonetheless, the quantity and quality of case studies, even though limited in scope, and the convergence of findings allow for learning and extrapolating wider lessons to different aspects of programmes, and they confirm that CHW programmes can be effective in providing promotive, preventive and limited curative health services for common childhood illnesses (eg, diarrhoea, pneumonia) in Sub-Saharan Africa.

Furthermore, the evidence base for policy making and programme development has been substantially strengthened in recent years through the collation and publication of several large reviews, ${ }^{5} 71112$ reports $^{13}$ and guides, ${ }^{6}$ some of which specifically address themselves to large-scale programmes, basing their recommendations on rigorous reviews and country case studies. ${ }^{67}$

Key insights from the existing evidence and their relevance for policy and practice are reflected in the following systems requirements, which are the foundational elements of functioning community health systems and CHW programmes:

1. Embeddedness, connectivity and integration.

2. Cadre differentiation and role clarity.

3. Sound programme design and management.

4. Ongoing monitoring, learning and adapting.

While this categorisation of elements is innovative, it in fact reflects key themes in both the established

\footnotetext{
${ }^{i i}$ Ongoing work in the WHO Collaborating Centre for Research and Training in Human Resources for Health at the University of the Western Cape in South Africa.
} 


\begin{tabular}{ll}
\hline Table 1 Typology of community health workers & \\
\hline When & What (illustrative examples) \\
\hline A. Episodic, 1-2 times a year, typically full time & $\begin{array}{l}\text { Distribution of preventive chemotherapy drugs for parasitic disease } \\
\text { control to general population. } \\
\end{array}$ \\
& $\begin{array}{l}\text { Distribution of long-lasting insecticide-treated bed nets for malaria } \\
\text { vector control to general population. }\end{array}$
\end{tabular}

B. Episodic, 3-6 times a year, typically full time

C. Monthly, typically part-time

D. Weekly, typically part-time

Administration of oral polio vaccine towards the eradication of polio to children less than 5 years old.

Community mobilisation for health promotion and environmental sanitation activities.

Community-based surveillance and reporting of births and deaths.

Home visits to pregnant women to encourage them to seek skilled antenatal and delivery care.

Home visits to postpartum women and newborns for health education and screening for illnesses.

Integrated management of common childhood illnesses such as pneumonia and diarrhoea.

\begin{tabular}{l}
$\begin{array}{l}\text { E. Daily, may be part-time or full time depending on } \\
\text { need }\end{array}$ \\
$\begin{array}{l}\text { Directly observed therapy for tuberculosis. } \\
\text { Contact tracing for confirmed and suspected cases of Ebola virus } \\
\text { on. }\end{array}$ \\
\hline
\end{tabular}

(particularly (2) and (3)) and the more recent (particularly (1) and (4)) literature. These elements will be discussed in turn below.

\section{Embeddedness, connectivity and integration}

Despite their diversity and variation, all CHW programmes have three characteristics in common:

1. They are part of a larger system of healthcare delivery and the health workforce, never just stand-alone programmatic interventions. ${ }^{6} 1415$

2. By their very nature they are 'boundary spanners' at the interface between the formal health system and communities, and thus have to be embedded in the health systems and in the communities they serve. ${ }^{14-16}$

3 . They inevitably interface with other sectors, resources and actors, adding complexity to a web of relationships that needs to be harmonised and integrated. ${ }^{6} 1517$

This has important implications for policy development and programme design:

1. Community systems are enormously diverse, even within countries and subregions, with complex, often 'hidden' structures, hierarchies, histories and traditions. Consequently, policy development for CHW programmes has to invest in understanding local systems, and design programmes that are flexible enough to 'fit' and be responsive to local realities. ${ }^{9} 18-20$

2. Strengthening local structures and processes has to be part of the investment in CHW programmes. ${ }^{10} 2122$

3. Paying attention to and building on existing CHW projects and practices are critical. While many successful large-scale programmes have been built on the foundations of projects initiated to respond to specific crises or needs, programmes 'helicoptered' into local systems fail to embed and connect. ${ }^{6} 171923$

4. Harmonising and integrating donor support and stakeholders from other sectors, as proposed by the Global Health Workforce Alliance in their CHW Framework, is an essential building block of CHW programme functionality.

\section{Cadre differentiation and role clarity}

The term 'CHW' has been used for a great diversity of cadres, roles, locations and identities. CHWs constituted of numerous close-to-community cadres, from paraprofessionals employed by the Ministry of Health with 1 year of training, providing services in health posts and communities, to volunteer workers and family carers with no or little training, support or link to the health system. Unfortunately, this conflation of healthcare providers at the community level into one cadre often obfuscates rather than enlightens our understanding of CHW programmes. ${ }^{24}$ Table 1 , which was developed as part of the technical paper and is reflected in the policy brief that informs this paper, ${ }^{3}$ provides a rough typology of the frequency and type of work that is assigned to CHWs. This is indicative rather than prescriptive, given the large variability in contexts and policy objectives of CHW programmes within and across countries. Other

iii The papers making up the framework can be found on the WHO website: http://www.who.int/workforcealliance/ knowledge/themes/community/en/. 
typologies have been developed inter alia by Olaniran $e t$ $a t^{t}$ and Perry and Zulliger ${ }^{5}$ (focusing particularly on the level of training and remuneration).

Very importantly cadre differentiation also has to address who becomes a CHW (gender, age, education level), how they are trained, supervised and supported, how their roles connect and integrate with other systems (eg, other layers of the health system, local government, education systems), and how such cadres fit into local contexts (histories, practices, experiences). The vast majority of the literature addresses some or all of these topics and has been reflected in all the reviews reflected in this paper.

For policy and programme design, the above means:

1. Being deliberate and explicit about what CHWs can and cannot do in the health system, focusing on aligning and clearly delineating educational criteria, roles and remuneration.

2. Regularly revisiting all elements of the above differentiation as well as their alignment to accommodate changes in services needs and human resource requirements (a monitoring and evaluation requirement).

\section{Sound programme design and people management}

Embedding community health programmes in wider contexts, being sensitive to local contexts and environments, and clarifying cadres and roles of CHWs will allow planning and management of programmes and people that fit and connect to existing (health and community) systems, and are relevant to the communities they aim to serve. ${ }^{621}$ Some of the key operational aspects of programme design are outlined below.

\section{Financing programmes}

As mentioned earlier, there have been several initiatives in recent years to understand costs and develop costing models for CHW programmes ${ }^{25}\left({ }^{6}\right.$ chapter 5$)$. They emphasised that direct and indirect investment and recurring costs of CHW programmes need to be estimated, and concluded that proper costing of a community health worker (CHW) program and assurance that those costs can be paid for on a sustainable basis are essential for an effective large-scale CHW program. Failure to do so has led to the demise of large-scale CHW programs in the $1980 \mathrm{~s}^{\prime}\left({ }^{6}: \mathrm{ix}\right)$.

\section{Managing people}

Planning for and managing all cadres of CHWs are among the most critical aspects of CHW programmes. Their geographical and organisational location on the periphery, often with ill-defined ownership and accountability and links to the formal health system, means that while they need particularly careful and attentive management, in practice they are often forgotten, infrequently supervised or ignored. ${ }^{26}$ It is therefore essential to bring CHWs into the centre of efforts to strengthen health systems.
Management entails recruitment and selection, training, supervision, and support, incentives and retention, and needs to be addressed from a systems (putting in place systems that allow people management) and an operations (implementing people management at the front line of service delivery) perspective. The literature has in recent years addressed questions of training and supervision, mostly focusing on specific programme areas (eg, MCH, HIV/AIDS, tuberculosis and so on).

All literature, whether recent or older, agrees that CHW programmes will inevitably fail unless they ensure that all CHW cadres receive the following:

1. Initial and continuing training commensurate with their roles.

2. Regular, skilled and supportive supervision.

3. Adequate and appropriate incentives (monetary or other).

4. Options for career progression.

It is also widely agreed that the quality and appropriateness of all components of management have a direct impact on both performance and retention of CHWs. ${ }^{26-30}$ While the detailed needs will vary substantially across and within countries, the core requirements are valid across all differences. Table 2 lists topics that need to be addressed, differentiating between design and implementation issues.

\section{Logistics and infrastructure}

Research has shown repeatedly that failure to ensure that CHWs reliably receive required medicines and supplies seriously undermines their ability to function and thus credibility in the communities they serve. ${ }^{6}{ }^{10} 13$ It is vital to plan for sustained logistics and infrastructure support from the start, keeping in mind that such support often poses substantial challenges, particularly in remote areas.

\section{Ongoing monitoring, learning and adapting}

Policy and programme design for CHW policies and programmes needs to be flexible enough to allow for continuous learning and adaptation to local contexts and requirements. Ongoing monitoring, learning and adaptation are thus essential to the success of programmes. ${ }^{631} 32$

Monitoring (of programmes, not just individual CHWs) relies on the collection and availability of accurate and timely data, which often is one of the weakest points of CHW programmes, particularly in large programmes. CHWs are dispersed in communities, with varying degrees of literacy, and often face severe time pressures when visiting households. Supervisors can play an important role in data collection, but have limited time as well. Evidence has shown that they should not spend too much of this time completing tick sheets instead of providing guidance and support to CHWs in their charge. ${ }^{6} 14$

Evidence also suggests that as far as possible CHW information systems should be designed to be integrated into existing routine primary healthcare information systems, taking care that essential, but not more than essential information is gathered. ${ }^{33} 34$ This is to ensure 
Table 2 Community health worker (CHW) programme design and implementation issues to be considered in policy development

\begin{tabular}{|c|c|c|}
\hline Design issues & Implementation issues & $\begin{array}{l}\text { Key questions for policy development (from } \\
\text { Perry et al } 2014 \text {, chapters 8-11) }\end{array}$ \\
\hline $\begin{array}{l}\text { Recruitment: } \\
\text { Align job requirements with job } \\
\text { descriptions and skills profile across all } \\
\text { cadres. } \\
\text { Explore whether there is a pool of people } \\
\text { eager to become CHWs and what } \\
\text { motivates them. } \\
\text { Ensure recruitment processes are } \\
\text { transparent, well-thought through and } \\
\text { clearly communicated. }\end{array}$ & $\begin{array}{l}\text { Recruitment: } \\
\text { The recruitment process and criteria are } \\
\text { clearly communicated and understood } \\
\text { by communities and pool of potential } \\
\text { applicants. } \\
\text { Relevant community structures are } \\
\text { involved in recruitment and selection. } \\
\text { Recruitment criteria and processes are } \\
\text { adhered to. }\end{array}$ & $\begin{array}{l}\text { What are the specific recruitment needs for } \\
\text { the CHW programme? } \\
\text { What are the CHW selection criteria? } \\
\text { What is the CHW recruitment process? } \\
\text { How do available resources influence } \\
\text { CHW recruitment? }\end{array}$ \\
\hline $\begin{array}{l}\text { Training: } \\
\text { Initial and continuing education } \\
\text { frameworks, structures and processes are } \\
\text { put in place. } \\
\text { Relevant and appropriate training materials } \\
\text { are developed in the local language. } \\
\text { Issues of certification and accreditation are } \\
\text { attended to. }\end{array}$ & $\begin{array}{l}\text { Training: } \\
\text { Trainers and training materials are available } \\
\text { (in the relevant local language). } \\
\text { Training is adapted to the needs of trainees } \\
\text { locally, their roles and local contexts. } \\
\text { Trainees are able to attend training. } \\
\text { There are opportunities for continuing } \\
\text { education. }\end{array}$ & $\begin{array}{l}\text { What sort of CHW and training programme } \\
\text { is being planned? } \\
\text { What level of education will be required for } \\
\text { entry to the programme? } \\
\text { How should the training programme be } \\
\text { organised? } \\
\text { Who should be responsible for the } \\
\text { governance and management of the } \\
\text { training programme? } \\
\text { How can optimal performance be achieved } \\
\text { through training? }\end{array}$ \\
\hline $\begin{array}{l}\text { Supervision and support: } \\
\text { Supervisions requirements are adequately } \\
\text { understood and resourced. } \\
\text { Supervisors are identified and designated. }\end{array}$ & $\begin{array}{l}\text { Supervision and support: } \\
\text { Supervisors are available, trained and } \\
\text { aware of their responsibilities. } \\
\text { Supervisors have the relevant tools, } \\
\text { equipment, infrastructure (eg, transport) } \\
\text { and support to fulfil their role. } \\
\text { Supervision is considered a priority. }\end{array}$ & $\begin{array}{l}\text { What are the objectives of CHW } \\
\text { supervision? } \\
\text { Is there a functioning PHC supervision } \\
\text { system and can it be adapted/expanded to } \\
\text { include CHWs? } \\
\text { Are there supervision standards and } \\
\text { guidelines for CHW performance? } \\
\text { Do the financial resources exist to sustain } \\
\text { a CHW supervision system? }\end{array}$ \\
\hline $\begin{array}{l}\text { Incentives: } \\
\text { Incentive structure and mix have been } \\
\text { discussed and planned for. } \\
\text { Adequate resources for incentives are in } \\
\text { place. } \\
\text { Mechanisms to make incentives available } \\
\text { are in place, whether for financial payments } \\
\text { or non-financial incentives. } \\
\text { Formalised remuneration. }\end{array}$ & $\begin{array}{l}\text { Incentives: } \\
\text { Incentives are understood and accepted } \\
\text { by local stakeholders and CHWs. } \\
\text { Incentives (whether monetary or other) are } \\
\text { regularly, reliably and fairly disbursed. } \\
\text { There is no nepotism or corruption in the } \\
\text { handling of incentives. } \\
\text { Inclusion in the payroll. }\end{array}$ & $\begin{array}{l}\text { What forms of incentives are there? } \\
\text { What are the decisions related to } \\
\text { incentives that need to be made? } \\
\text { What incentives are culturally, socially and } \\
\text { financially acceptable among CHWs? } \\
\text { What are different stakeholders' } \\
\text { expectations with regard to incentives? }\end{array}$ \\
\hline $\begin{array}{l}\text { Career pathways: } \\
\text { If possible, career paths for different } \\
\text { cadres of CHWs are developed to allow for } \\
\text { advancement and progression (and thus } \\
\text { improving retention). }\end{array}$ & $\begin{array}{l}\text { Agreements between the government, } \\
\text { Ministry of Health, professional regulatory } \\
\text { bodies and training institutions have been } \\
\text { put in place. }\end{array}$ & \\
\hline
\end{tabular}

PHC, Primary Health Care.

evidence-based planning and management without creating unnecessary burdens on health workers and duplications within the health system. Crucially, information collected should actively be used to understand programme implementation, strengths and weaknesses, challenges and mistakes. Throughout the system problems and even failures should be understood as learning opportunities, leading to adaptations and improvements.

\section{CONCLUSIONS}

There is strong evidence that with appropriate training, supervision, motivation and logistics management, CHWs are effective at providing preventive, promotive and limited curative PHC services at the community level in LMICs, including in Sub-Saharan Africa. They can also improve health outcomes, especially for child health. However, quality and consistency of services are variable and sometimes poor.

History has shown that CHW programmes are complex to design and implement, needing a careful balance of support and guidance from the centre and ability to adapt to local contexts and realities. They are unsustainable if considered a cheap or short-term solution to shore up broken health systems.

CHW programmes are an investment in health systems strengthening and community resilience as they 
represent enormous potential to improve health and community systems. The decision to make this investment for programmes at scale is a policy decision that requires engagement with policy makers and national-level stakeholders from the Ministry of Health and other sectors including non-governmental organisations and even politicians. While the evidence base is uneven and mixed, it is exceptionally rich by now, providing enough insight and knowledge to strengthen, scale and sustain CHW programmes throughout Africa.

Acknowledgements We acknowledge with appreciation the contribution of $\mathrm{Dr}$ Delanyo Dovlo and other WHO colleagues to the original review.

Contributors JN commissioned the initial review, which was conducted and written by UL and NAYT-D. This paper was written by UL and reviewed and revised by NAYT-D and JN.

Funding This study was funded by WHO.

Competing interests None declared.

Patient consent Not required.

Provenance and peer review Not commissioned; externally peer reviewed.

Data sharing statement No additional data are available.

Open access This is an open access article distributed in accordance with the Creative Commons Attribution Non Commercial (CC BY-NC 4.0) license, which permits others to distribute, remix, adapt, build upon this work non-commercially, and license their derivative works on different terms, provided the original work is properly cited, appropriate credit is given, any changes made indicated, and the use is non-commercial. See: http://creativecommons.org/licenses/by-nc/4.0

\section{REFERENCES}

1. WHO, 1978. Declaration of alma ata international conference on primary health care. Alma Ata. Available from: http://www.who.int/ publications/almaata declaration en pdf

2. WHO. Community Health Workers: Implications for large-scale CHW programs in the WHO African Region. Brazzaville, 2016.

3. World Health Organization Regional Office for Africa, 2017. Community Health Worker Programmes in the WHO African Region: Evidence and Options. Available from: http://www.chwcentral.org/ sites/default/files/WHO\%20CHW\%20Policy\%20Brief\%202017.pdf

4. Olaniran A, Smith H, Unkels R, et al. Who is a community health worker? - a systematic review of definitions. Glob Health Action 2017;10:1272223.

5. Perry H, Zulliger R. How effective are community health workers? an overview of current evidence with recommendations for strengthening community health worker programs to accelerate progress in achieving the health-related millenium development goals. Baltimore, Maryland: Johns Hopkins Bloomberg School of Public Health The MDG Health Alliance, 2012.

6. Perry H, Crigler L, Hodgins S, 2014. Developing and strengthening community health worker programs at scale a reference guide and case studies for program managers and policymakers Maternal and Child Health Integrated Program (MCHIP). Available from: http:// www.chwcentral.org/sites/default/files/MCHIP_CHWRefGuide.pdf

7. Bhutta ZA, Zohra S, Lassi GP. Global experience of community health workers for delivery of health related millennium development goals, 2010.

8. Schneider H, Okello D, Lehmann U. The global pendulum swing towards community health workers in low- and middle-income countries: a scoping review of trends, geographical distribution and programmatic orientations, 2005 to 2014. Hum Resour Health 2016;14:1-12.

9. Perry H, Zulliger R. How effective are commnity health workers? summary report. Baltimore, 2012

10. Lehmann U, Sanders D. Community health workers : what do we know about them? the state of the evidence on programmes, activities, costs and impact on health outcomes of using community health workers. Geneva, 2007.

11. Lewin S, Munabi-Babigumira S, Glenton C, et al. Lay health workers in primary and community health care for maternal and child health and the management of infectious diseases. Cochrane Database Syst Rev 2010;3:CD004015.
12. Perry HB, Zulliger R, Rogers MM. Community health workers in low-, middle-, and high-income countries: an overview of their history, recent evolution, and current effectiveness. Annu Rev Public Health 2014;35:399-421.

13. The Earth Institute, 2011. One million community health workers. Available from: http://www.millenniumvillages.org/uploads/ ReportPaper/1mCHW TechnicalTaskForceReport.pdf

14. Kok MC, Dieleman M, Taegtmeyer M, et al. Which intervention design factors influence performance of community health workers in low- and middle-income countries? a systematic review. Health Policy Plan 2015;30:1207-27.

15. Schneider $\mathrm{H}$, Lehmann U. From community health workers to community health systems: time to widen the horizon? Health Systems \& Reform 2016;2:112-8.

16. Kok MC, Broerse JEW, Theobald S, et al. Performance of community health workers: situating their intermediary position within complex adaptive health systems. Hum Resour Health 2017;15:1-7.

17. Kok MC, Kane SS, Tulloch O, et al. How does context influence performance of community health workers in low- and middleincome countries? evidence from the literature. Health Res Policy Syst 2015;13:13

18. Zulu JM, Kinsman J, Michelo C, et al. Integrating national community-based health worker programmes into health systems: a systematic review identifying lessons learned from low-and middleincome countries. BMC Public Health 2014;14:987.

19. Lehmann U, Gilson L. Actor interfaces and practices of power in a community health worker programme: a South African study of unintended policy outcomes. Health Policy Plan 2012;28:1-9.

20. Naimoli JF, Perry HB, Townsend JW, et al. Strategic partnering to improve community health worker programming and performance: features of a community-health system integrated approach. Hum Resour Health 2015;13:46.

21. Tulenko K, Møgedal S, Afzal MM, et al. Community health workers for universal health-care coverage: from fragmentation to synergy. Bull World Health Organ 2013;91:847-52.

22. Leban K, 2011. How social capital in community systems strengthens health systems:people, structures, processes. Available from: http://www.coregroup.org/storage/Program Learning/ Community_Health_Workers/Components_of_a_Community_ Health_System_final10-12-2011.pdf

23. Pallas SW, Minhas D, Pérez-escamilla R. Community health workers in low- and middle-income countries: what do we know about scaling up and sustainability ? 2013: 1-10.

24. Frontline Healthworker Coalition, 2013. A commitment to community health workers: improving data for decision-making. Available from: http://frontlinehealthworkers.org/chwreport/

25. Dahn B, Woldemariam AT, Perry H. strengthening primary health care through community health workers : investment case and financing recommendations, 2015.

26. Strachan DL, Källander $\mathrm{K}$, ten Asbroek $\mathrm{AH}$, et al. Interventions to improve motivation and retention of community health workers delivering integrated community case management (iCCM): stakeholder perceptions and priorities. Am J Trop Med Hyg 2012;87(5 Suppl):111-9.

27. Ludwick T, Brenner JL, Kyomuhangi T, et al. Poor retention does not have to be the rule: retention of volunteer community health workers in Uganda. Health Policy Plan 2014;29:388-95.

28. Mahmud N, Rodriguez J, Nesbit J. A text message-based intervention to bridge the healthcare communication gap in the rural developing world. Technol Health Care 2010;18:137-44.

29. Strachan DL, Källander K, Nakirunda M, et al. Using theory and formative research to design interventions to improve community health worker motivation, retention and performance in Mozambique and Uganda. Hum Resour Health 2015;13:25.

30. Raven J, Akweongo P, Baba A, et al. Using a human resource management approach to support community health workers: experiences from five African countries. Hum Resour Health 2015:13:45

31. Hodgins S, Crigler L, Simon L, 2013. Scaling up and maintaining effective community health worker programs at scale. Available from: http://www.mchip.net/sites/default/files/mchipfiles/14_CHW_ Scale.pdf

32. Jaskiewicz W, Tulenko K. Increasing community health worker productivity and effectiveness: a review of the influence of the work environment. Hum Resour Health 2012;10:38.

33. Singh P, Sachs JD. 1 million community health workers in subSaharan Africa by 2015. Lancet 2013;382:363-5.

34. Mitsunaga T, Hedt-Gauthier B, Ngizwenayo E, et al. Utilizing community health worker data for program management and evaluation: systems for data quality assessments and baseline results from Rwanda. Soc Sci Med 2013;85:87-92. 